\title{
How AI Manufactures a Smile: Tung-Hui Hu Interviews Artist Elisa Giardina Papa on Digital Labor
}

\section{TUNG-HUI HU}

Associate Professor of English and Digital Studies, University of Michigan, Ann Arbor

\section{ELISA GIARDINA PAPA}

Artist

\section{ABSTRACT}

This conversation between scholar and poet Tung-Hui Hu and artist Elisa Giardina Papa addresses new forms of precarious labor emerging within artificial intelligence economies. Together they examine a global infrastructure of low-paid human microworkers who "clean" data and train machine vision algorithms, labelling, categorizing, annotating, and validating massive quantities of visual data. $\mathrm{Hu}$ and Giardina Papa discuss methods and psychological theories underpinning affective computing in the context of Giardina Papa's latest art project, which explores the labor of producing and cleansing data sets of human expressions. A number of AI systems that supposedly recognize, interpret, and simulate human affects base their algorithms on flawed understandings of human emotions as universal, authentic, and transparent. Increasingly, tech companies and American government agencies like the Transportation Security Administration are leveraging this supposed transparency to develop software that identifies, on the one hand, consumers' moods and, on the other hand, potentially dangerous airline passengers. In this exchange, Hu and Giardina Papa consider both the historical and present-day implications of this demand for legibility and transparency.

THH: You recently took on a three-month gig as a low-wage human trainer for various AI systems, spending time annotating and correcting visual data, such as recognizing emotions from facial images and shapes for computer vision algorithms. This must have been striking, as you are of course also a visual artist, engaged in another form of work which relies, in a paradoxical way, on the production and recognition and circulation of images. Did you find any similarities or ironies as you performed both kinds of image work? 
EGP: I am finishing a new art project that focuses on the invisible human infrastructure that sustains artificial intelligence. It is the third in a series of works exploring the ways in which labor is reframed by digital economies and AI automation (Technologies of Care, 2016, and Labor of Sleep, 2017, respectively). The latest project — which is still in progress - investigates the labor of "cleaning data" for machine vision systems and affective computing. While doing the preliminary research, I ended up working for several so-called "human-in-the-loop" services-companies that provide "clean" datasets to train AI systems or, put another way, companies that outsource the work of cleaning data to thousands of underpaid and precarious micro-task workers. These offshore "clickworkers" label, categorize, annotate, and validate massive quantities of digital records, which are later used to train a variety of neural networks.

I started the research/work this winter while I was living in Palermo, in Sicily. Among the tasks I performed there was the image segmentation for machine vision algorithms used in self-driving cars. That is, I would outline objects' boundaries with polygonal circuits and then label them. After full days of tracing and tagging shapes in these videos, I would go out for walks in the city, and without initially realizing it, I started to name and visually enclose objects - I would pay attention to their contours, and I would be particularly bothered by obstructions. In other words, my eyes kept trying to reorganize my surroundings according to fixed taxonomies and orderly bounding lines. The problem is, I don't know how familiar you are with Palermo, or southern Italian cities in general, but they defy and exceed the logic of capture and control. If you try to grasp them, they might end up grasping you instead. When Walter Benjamin traveled through Naples - a city that is historically and culturally quite similar to Palermo - he defined it as porous and commingled, a space in continuous metamorphosis, a theater of common life in which the authority of northern European rationality faltered and broke down. ${ }^{1}$ And honestly, if I imagine a self-driving car trying to find its way through the unruly narrow alleys of the Vucciria neighborhood-where I was living at the time-I can't help but smile. I also have to ask myself, why exactly would we ever need a Google self-driving car in Palermo? The corporate visions of a future based on capture, control, reduction, and optimization cannot but fail there, and often for the best of reasons.

Similarly, art does not surrender so easily to the logic of capturing and fixing signification. Think of feminist surrealist artist Meret Oppenheim's work. Take, for example, the work entitled Object (Breakfast in Fur). It's a teacup, a saucer, and a spoon - all covered with fur. It is an art work, but then: is it a domestic object or a sculptural one? A comforting or a disquieting one? A stuffed animal of sorts or a sex toy?

THH: Is it possible to speak of solidarity between the labor of a "data cleaner"-labor which is heavily concentrated in the Global South, in countries such as Uganda and Kenya - and the free labor of an everyday user, creating, say, a web history or writing reviews, or is this a false equivalence?

EGP: It's a false equivalence but a useful provocation. The concept of free labor in relation to internet economies was mobilized by Tiziana Terranova as a reaction to the rhetoric of gift and 
sharing economies that was dominating the discourse on internet culture in the early 2000 s. $^{2}$ Terranova clarified for us that the user of the internet is first and foremost used. Today, now that we have finally let go of naive technological utopianism, it has become evident that the user is the ultimate site of extraction from which data and surveillance capitalism thrives and profits - and of course the immense capital thus accumulated will never be equally redistributed.

We also know that we have been unwittingly training machine-learning systems for years now by solving captchas that prompt us to transcribe door numbers and mangled letters, or to select storefronts, traffic lights, and animal pictures from image grids. Ironically, we have been doing this to prove that we are humans and not just working machines-CAPTCHA being an acronym for Completely Automated Public Turing test to tell Computers and Humans Apart.

Specifically, the task of selecting images - such as road signs-from a grid according to predetermined labels has been used by Google to outsource the labor of cleaning the visual data necessary to train self-driving cars. It is in fact a very similar task to those performed daily as a job by thousands of gig workers. It is also one of the actions I performed repeatedly during the period of my research, but let me be clear: I did this for a limited amount of time, and while I did make some money, my livelihood did not fully depend on this work. Therefore, this is the point at which the equivalence between users - reframed as free workers - and gig workers needs to be dropped, because the data-cleaners who perform this labor for eight or more hours a day often do it because no other jobs are available to them — at least in the short term. They cannot simply opt out.

THH: A new landmark study by five psychologists ${ }^{3}$ rebuts the idea that you can reliably "fingerprint" emotion based on facial expression because it ignores other contexts: as the authors write, "tech companies may well be asking a question that is fundamentally wrong." In a comment to a journalist, one of the study's authors even raised the spectre of emotion recognition being used in a court of law or in hiring - even though it might be accurate only $30 \%$ of the time. What is at stake for you when you explore the question of how these laborers are tasked to produce, in your words, a "consistent ground-truth" to the idea of emotion? In more philosophical terms, you cite Édouard Glissant when you argue that this regime disallows the possibility for opacity: our inner emotional lives are supposed to be reflected in our faces. Can you speak more about this?

EGP: Among the tasks I performed during my research/work for data cleaning companies was also, as you mention, the taxonomization of human emotions for affective computing. I annotated hundreds of images of human facial expressions, and I recorded videos of myself acting out emotions to create datasets for AI systems that supposedly recognize, interpret, and simulate human affects. At the beginning, several of my videos were rejected. Apparently my facial expressions did not match the crude and normative categories into which they were supposed to fit. My face was not happy enough, or at least not happy in the right way. I had a particularly difficult time executing a "happily disgusted face." I was never able to learn whether this rejection originated from an algorithm or, for example, another gig worker who perhaps due to cultural differences interpreted my facial expressions in a different way. That's how I became interested in the theories and methods underpinning artificial emotional intelligence. 
One of the methods currently used - and also heavily criticized - is FACS (Facial Action Coding System) developed in the late seventies by American behavioralists Paul Ekman and Wallace V. Friesen. ${ }^{4}$ It is an anatomically-based method for describing all observable facial movements related to every emotion - fear, for example, is coded as: eyebrows raised and drawn together, upper eyelids raised, lips drawn back toward the ears. This is a system based on an understanding of emotions that relies on ideas of universality, transparency, and truth. That is, it poses emotions as universal - as opposed to culturally or contextually determined — and as entities that can be reduced to or measured by an ideal, standardized scale. It also asserts that emotions can be fully revealed and made transparent through the movements of our facial muscles. Consequently, a trained observer would be able to see our inner lives leak into our micro-expressions even when we try to conceal them. ${ }^{5}$ Increasingly, tech companies and American government agencies like the Transportation Security Administration are leveraging this supposed transparency to develop software which identifies, on the one hand, consumers' moods and, on the other hand, potentially dangerous airline passengers. ${ }^{6}$ Several psychologists and civil liberties experts have voiced their concerns about the validity and accuracy of this method-specifically with respect to its implementation in TSA programs. ${ }^{7}$

What is most troubling about FACS and similar methods currently used in automated systems is this unchallenged assumption of transparency, because hegemonic demands for legibility and transparency are never devoid of political implications. For example, the relationship between alterity and transparency is a complicated one, and one that bears the traces of imperial and colonial conquest. That's why the writing of Édouard Glissant is relevant and useful here. Alterity in Western thought, the Martiniquan philosopher and poet tells us, has always been inextricable from a requirement for transparency - that is, the requirement of being reduced, measured, and understood in relation to an idealized, universal Western scale, norm, or system. ${ }^{8}$ Indeed, transparency ultimately aims at grasping. It "contains the movement of hands that grab their surroundings and bring them back to themselves. A gesture of enclosure if not appropriation." Hence, thinking with Glissant through opacity - rather than transparency - is about becoming sensitive to the limits of every method based on absolute truths and presumed universality. It is also about disallowing the conquering of that which cannot and should not be reduced. ${ }^{10}$

THH: You've done some historical research on the idea of quantifying emotional transparency, going back to nineteenth-century French neurologist Guillaume Duchenne de Boulogne, who did his research by electrically stimulating facial muscles. The teacher of Charcot, he's now perhaps best known for the "Duchenne smile," a smile that crinkles the muscle around one's eyes; scientists claim this is the only real smile among many fake or insincere smiles. As Duchenne wrote, only the "sweet emotions of the soul" could produce this type of smile. Can you tell us about this research? Did you find anything that surprised you in the archives? Doesn't the drive towards producing and stabilizing authenticity recall a racialized history, where non-white people were described as either too simple to conceal their inner joy, or too simple to have a soul?

EGP: I researched the archive of Duchenne de Boulogne because there seems to be an uncomfortable fil rouge that links FACS — which we just discussed — with Duchenne's nineteenth- 
century experiments. The similarities are traceable in the attempt to establish and stabilize a discrete set of authentic, universal, and transparent emotions. But, more specifically, what troubled me most about Duchenne's work is the relationship he establishes between emotional agency and control. Put simply: who gets to control her own emotions and who doesn't?

Indeed, the way we understand emotions is historically marked by a Western-centric hierarchy that privileged thought and reason over emotions, and likewise mind over body. Within this framework, as Sara Ahmed has argued, the ability to be in control of emotions and to "appropriately" display them has come to be seen as a characteristic of some bodies and not others. ${ }^{11}$ Feminist scholars have written extensively on how femininity has been linked with an excess of emotionality-when not linked with outright hysteria. And in your own writing on lethargy, you refer to Sianne Ngai's definition of "animatedness." That is, "the old stereotype of racialized subjects as either excessively or minimally emotional and expressive - and, simultaneously, puppet-like and lacking control over their own bodies, as if they had been animated by another." 12 In the writings of the French neurologist, apparently there is no direct reference to gender and racial stereotyping. Yet, throughout the Mecanisme de la physionomie humaine, Duchenne poses himself as a sort of puppet master who, armed with a new technology (localized muscle electrization) could impress the true emotions of the soul upon the faces of his patients - who were often described as either incapable of emoting properly or emotionally incapacitated. Duchenne puppeteers, manipulates, and acts upon their faces to obtain, in his words: "the expression that [he wants] as he [feels] it."13 In a particularly dark passage, Duchenne writes about the experiments carried out to capture what he calls the facial muscle of "lasciviousness." One of the "models" recruited for these experiments is an unidentified French woman who is affected by a nearly complete loss of vision. Duchenne writes that due to the woman's inability to understand the gestures or poses that he wanted her to perform, he was "obliged to position her and dress her as if she were a mannequin."14 Duchenne arranges the woman's body in specific poses and adds props - such as a white veil and a small cross - and electrically stimulates her facial muscles to demonstrate the differences between the expression of celestial love and that of terrestrial love. In Duchenne's words: "I have performed a metamorphosis by changing the purest, most angelic smile and the most saintly ecstasy ... into the most provocative and licentious by means of combining a strong contraction of this muscle to the other features; in so doing I transformed virgins into bacchantes." 15 

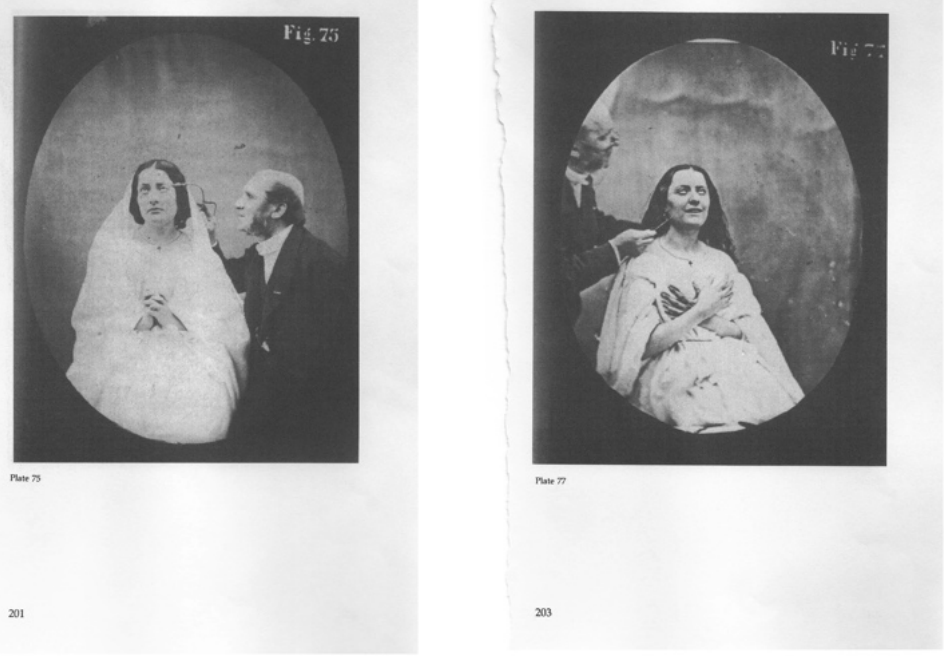

\section{Figure 1. Elisa Giardina Papa, work in progress on emotional AI, 2019-, still frame from the video capturing Duchenne de Boulogne's book Mecanisme de la physionomie humaine, 1862. Courtesy of the artist.}

THH: One of the things I love in an earlier work of yours, Technologies of Care, is that the subjects you interview ask you questions and talk back; they are not populations described by an objective scientist or journalist. For instance, it sounds like you anonymized the workers at their request, rather than ventriloquizing their words. I'm also fascinated by the aesthetics of it, starting with the installation itself: in the places I've seen it, the installation invites viewers to sit down facing the interview subjects, even as its plywood enclosure is slightly reminiscent of a makeshift work cubicle. How do you situate yourself next to (or against) reportage or (auto-) ethnography of similar subjects? And how do you think about the visual form of the AI-training platforms that you worked for?

EGP: I started the research for Technologies of Care after I spoke with a friend in Sicily who had recently started to work as an online micro-laborer. She was doing short translations-English to Italian - but had also recently experimented with some gigs based on private online chats. She would talk in Italian twice a week at night with one client from the UK to aid his sleep. Both services were delivered through the same gig-economy platform. That's when I began to investigate the economics and politics of digitally outsourced care and affective labor. I got in touch with several other workers online. I had conversations with an $\mathrm{ASMR}^{16}$ artist, an online dating coach, a fetish video performer and fairytale author, a social media fan-for-hire, a nail wrap designer, and a customer service operator, among others. Based in Brazil, Greece, the Philippines, Venezuela, and the United States, they worked as anonymous freelancers, connected via labor outsourcing platforms to customers mainly located in the US, the UK, and Canada. In the work logs, I also included online conversations I had with chatbots that reproduce emotional labor-algorithms programmed to simulate emotional intelligence. What I tried to do with Technologies of Care was 
to trace how preexisting inequalities in care work-labor exploitation, the feminization of caregiving paired with its lack of recognition as waged work, its social devaluation due to its proximity to intimacy, and the international division of labor between Global North and Global South — have been both exacerbated and dissimulated by digital economies.

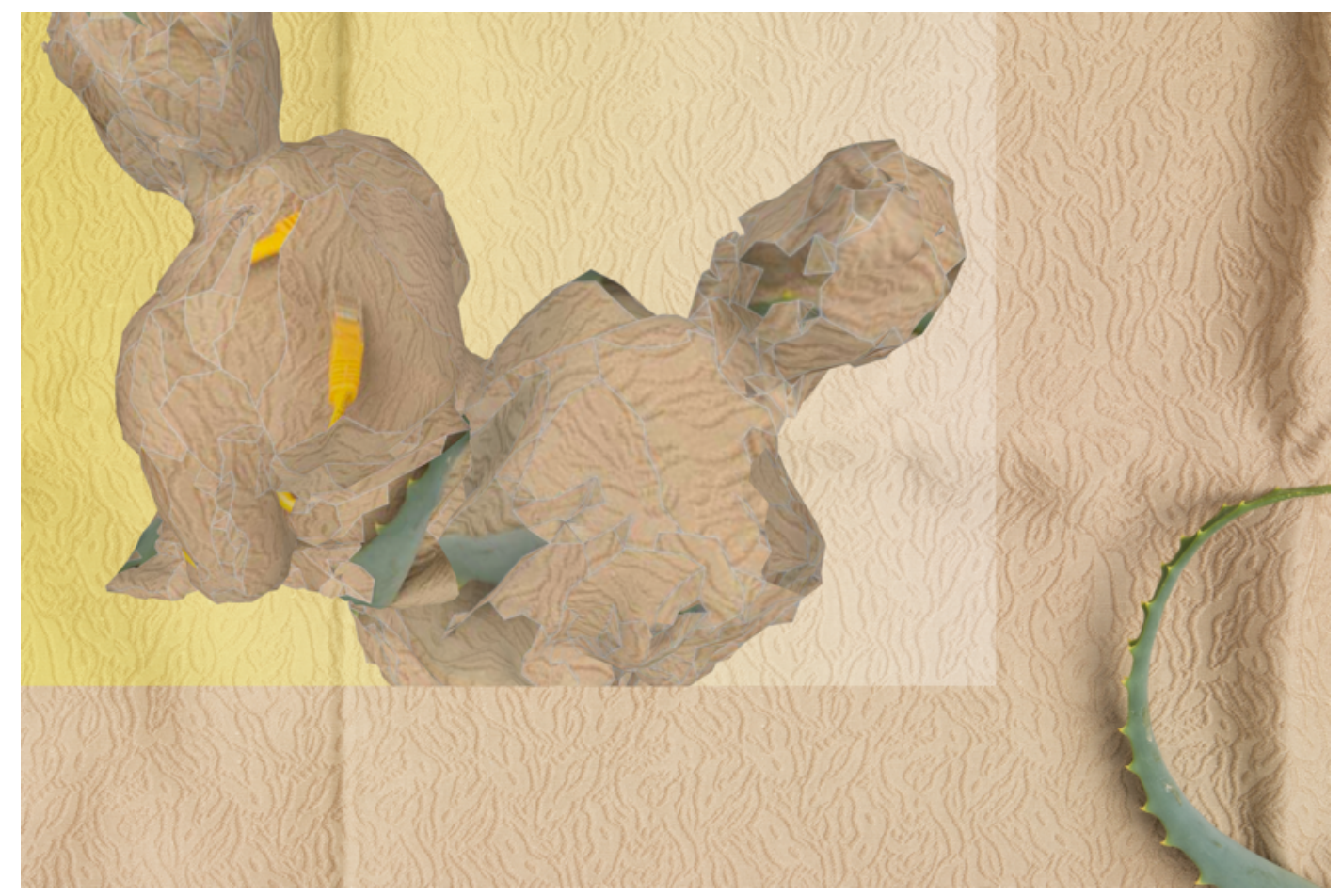

Figure 2. Elisa Giardina Papa, Technologies of Care, 2016, video installation, still frame from the video. Courtesy of the artist.

The first woman I talked with, after my friend in Sicily, was a biology professor from Venezuela with a master's degree in immunology and a Ph.D. in biochemistry. She worked as a team with her daughter under a single male-identified profile for several gig-economy platforms. Among other services, she was ghost-writing homework for high school students, most of whom were located in the United States. She intentionally used a male profile to circumvent gender wage devaluation, stating: "I work in academia, I am no stranger to the wage gap and heteronormativity in our society. I am sure that women make less than their male counterparts for the same work, and I am also Latin American. Being a Latina woman makes me more prone to receiving less for the same hard work." ${ }^{\prime 17}$ After we talked, she decided to participate in the project, and she also asked to remain anonymous. This request set the parameters for the resulting work. I ended up portraying the workers as abstract, rotating three-dimensional shapes, my intention being to respect their privacy while at the same time hinting at the ways in which online gig economies abstract away workers' subjectivities by reducing them to packets of time that can be activated on demand. The problem 
of course is that, as Franco Berardi has diagnosed in relation to info-labor, "Depersonalized time has no rights, nor any demands. It can only be either available or unavailable." 18 In this new economic paradigm, capital does not recruit people but rather buys packets of time that are separated from their interchangeable and occasional bearers. ${ }^{19}$ The textures of the threedimensional renderings in the videos echo the small details of the laborers' working/domestic environments that I noticed during our conversations: the surface of a pillow in a living room, that of a curtain in a bedroom or a tablecloth in a kitchen. The material aspects of the installation extend these video textures in the physical space of the gallery, while at the same time recreating, as you described, a makeshift work cubicle. This enclosing structure allows visitors to experience the piece in a protected, intimate space, by visually and auditorily separating the work from the rest of the gallery or museum space.

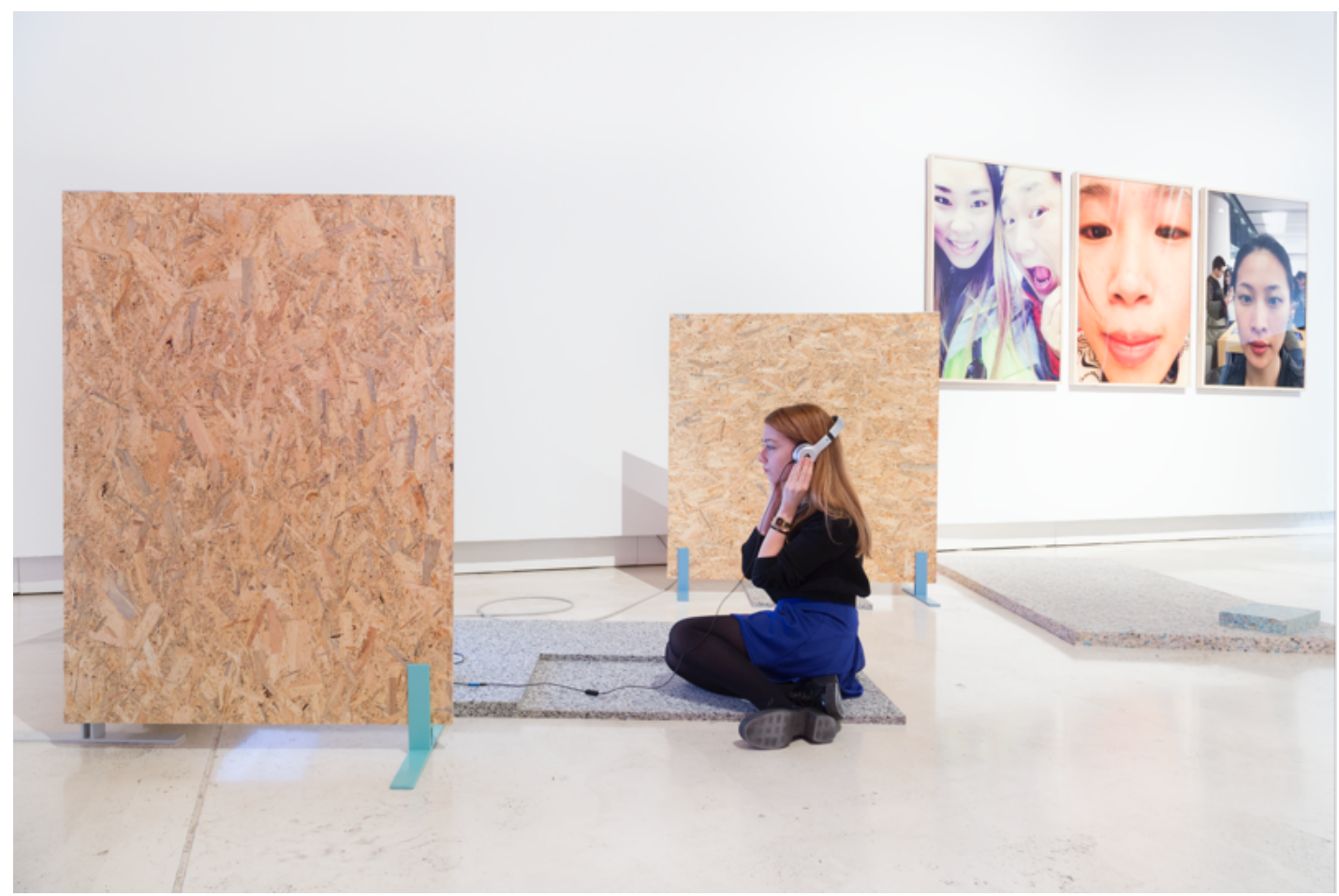

Figure 3. Elisa Giardina Papa, Technologies of Care, 2016. Installation view, XVI Quadriennale d'Arte, Palazzo delle Esposizioni, Rome, 2017. Courtesy of the artist. 


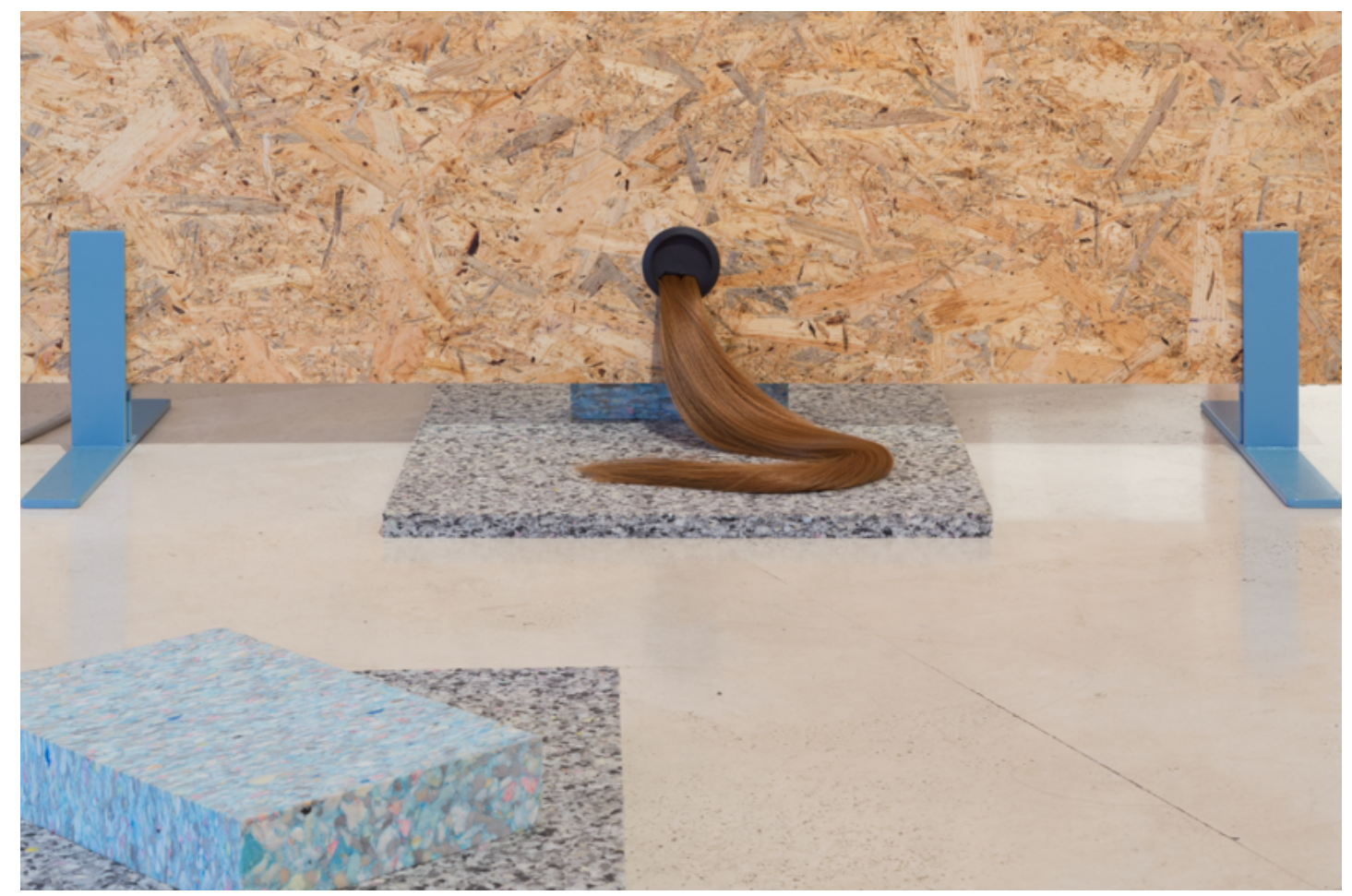

Figure 4. Elisa Giardina Papa, Technologies of Care, 2016. Installation view, XVI Quadriennale d'Arte, Palazzo delle Esposizioni, Rome, 2017. Courtesy of the artist.

THH: With Nupur Mathur and Bathsheba Okwenje, you are also part of Radha May, an artist that has a single female identity and speaks as a singular voice - as an "I" and not a "we." It seems to me that as an "experiment in reimagining a singular identity," as you put it in a previous interview, Radha May is a powerful model for how to be together today - and how identities can be woven together but not merged. There are many other models of collective behavior and collective identity within digital culture, whether the metaphor of a swarm or virality, of a global cosmopolitan consciousness, or, more literally, the crowd labor platforms that merge, say, human and robot labor into a single product, or 600 writers into a single virtual avatar. Can you talk about the differences or tensions between the "Radha May" model and these other ones, and perhaps the importance of making Radha May gendered female?

EGP: Yes, Radha May comprises three different women: Nupur from India, Bathsheba from Uganda, and myself from Italy. We met in the United States in 2012, and we came together because of common interests in gender, borders, forgotten archives, and hidden histories. Since the beginning, we have discussed intensively how to have a collaborative practice that could be open to the complexities and dissonances of our different cultural backgrounds, identities, bodies, and experiences. Even now, we approach our projects with a range of opinions and cultural assumptions, some of which contradict and clash. But we try to work through these with sensitivity 
until we arrive at a point or an approach that resonates with the project and simultaneously allows for any dissonances to coexist without necessarily cohering. For instance, the first project we did together, When the Towel Drops, Volume 1, Italy, is an art installation and a performance that investigates the censored representation of women, femininity, queerness, and sexuality in Italian cinema. The work compiles and reveals hundreds of scenes that were removed from publicly screened films in Italy in the 1950s and 1960s. It traces a history of the institutional regimentation of female and queer bodies and desires. By working together, we were able to adopt a position embedded in Italian politics, culture, and history, as well as one that was removed from these. We worked through the censorship archive from positions that encompassed familiarity, first encounters, and sometimes prolific misunderstandings, all occurring simultaneously. The resulting project benefited greatly from this.

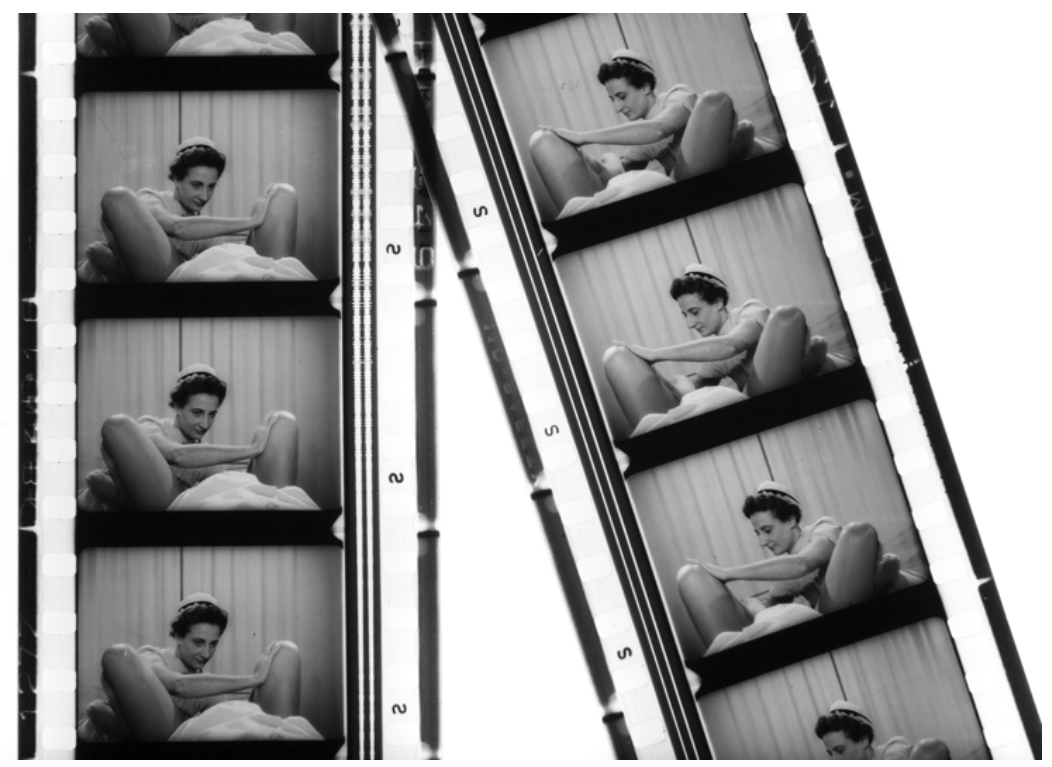

Figure 5. Radha May (Elisa Giardina Papa, Nupur Mathur, Bathsheba Okwenje), When the

Towel Drops, Volume 1, Italy, 2015-2019, 35mm film installation, detail of a film scene censored from "Brink of Life," Ingmar Bergman (1958). Courtesy of the artists and MiBACT. 


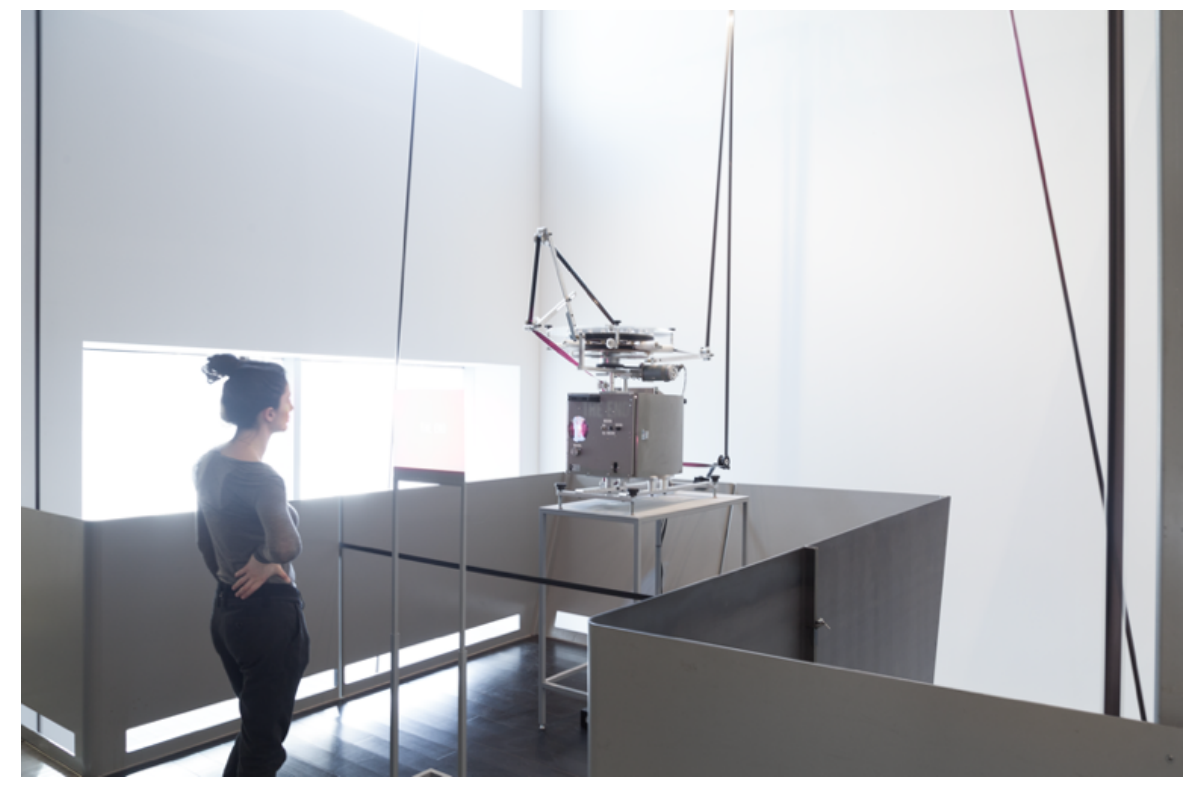

Figure 6. Radha May (Elisa Giardina Papa, Nupur Mathur, Bathsheba Okwenje), When the Towel Drops, Volume 1, Italy, 2015-2019, 35mm film installation, installation view, Granoff Center for the Creative Arts, Providence, 2015. Courtesy of the artists.

\section{ENDNOTES}

1. Walter Benjamin, and Asja Lācis "Naples," in Reflections: Essays, Aphorisms, Autobiographical Writing, trans. Peter Demetz (New York: Schocken Books, 1986), 163-173.

2. Tiziana Terranova, "Free Labor," in Network Culture: Politics for the Information Age (London: Pluto Press, 2004), 73-94.

3. Lisa Barrett, Ralph Adolphs, Stacy Marsella, Aleix M. Martinez, and Seth D. Pollak, "Emotional Expressions Reconsidered: Challenges to Inferring Emotion from Human Facial Movements," Psychological Science in the Public Interest 20, no. 1 (2019), 1-68.

4. See Paul Ekman and Wallace V Friesen, Unmasking the Face: A Guide to Recognizing Emotions from Facial Clues (Englewood Cliffs, N.J: Prentice-Hall, 1975), and Paul Ekman, Emotions Revealed: Recognizing Faces and Feelings to Improve Communication and Emotional Life (New York: St. Martin's Griffin, 2007).

5. See Paul Ekman, Telling Lies: Clues to Deceit in the Marketplace, Politics, and Marriage (New York: W.W. Norton, 2009).

6. Lisa Feldman Barrett, "What Faces Can't Tell Us," New York Times, February 28, 2014, https://www.nytimes.com/2014/03/02/opinion/sunday/what-faces-cant-tell-us.html.

7. The TSA implemented parts of this method in their controversial program SPOT: Screening of Passengers by Observation Techniques. According to a classified TSA document, the trained 
agents could, for instance, give you one point — on a scale of potential pericolosity — if you were fidgeting, two points if you had a cold stare, and three points for a fast eye-blink rate. Conversely, they would subtract two points for an "apparent" married couple or a woman over the age of 55the points of deduction for a man would only come after 65 years old. See Jana Winter and Cora Currier Exclusive, "TSA's Secret Behavior Checklist To Spot Terrorists," The Intercept, March 27, 2015, https:/theintercept.com/2015/03/27/revealed-tsas-closely-held-behavior-checklist-spotterrorists/. And on the fallacy of profiling through behavioral screening, see: Bernard E. Harcourt, "Search and Defend," New York Times, August 25, 2006, https://www.nytimes.com/2006/08/25/opinion/search-and-defend.html.

8. See Édouard Glissant, Poetics of Relation, trans. Betsy Wing (Ann Arbor: University of Michigan Press, 1997), 191-192

9. Ibid.

10. On the influence of Édouard Glissant's theorization of opacity in the fields of media studies, queer theory, and contemporary art, see Zach Blas and Jacob Gaboury "Biometrics and Opacity: A Conversation," Camera Obscura 92, vol. 31, no. 2 (September 1, 2016):155-165; and Zach Blas, "Opacities: An Introduction,” Ibid.,149-153.

11. Sara Ahmed, The Cultural Politics of Emotion (London: Routledge, 2004), 4.

12. Tung-Hui Hu, "Laugh Out Loud," in Assembly Codes: The Logistics of Media, eds. Matthew Hockenberry, Nicole Starosielski, and Susan Zieger (Durham, NC: Duke University Press, in press). For the theorization of "animatedness" by Sianne Ngai, see Sianne Ngai, Ugly Feelings (Cambridge, Mass.: Harvard University Press, 2007).

13. Duchenne de Boulogne, The Mechanism of Human Facial Expression, trans. Andrew Cuthbertson (Cambridge, England: Cambridge University Press, 1990), 106.

14. Ibid., 105.

15. Ibid., 110.

16. As described by the ASMR artist: "ASMR stands for autonomous sensory meridian response, and basically this is when people have or receive a tingling feeling and sensation that occurs either on the top of the head or down the spine. ASMR can be triggered in many different ways, and it's up to an individual to discover what their trigger is." See Elisa Giardina Papa, "Technologies of Care" (2016), downloadable at Rhizome, http://rhizome.org/editorial/2016/oct/04/the-download-technologies-of-care/. According to Science Daily, "There are over 13 million ASMR videos on YouTube-including medical examinations, haircuts and massages, and folding towels tutorials - which people watch to relax, relieve stress or sleep better."

https://www.sciencedaily.com/releases/2018/06/180621101334.htm.

17. See Elisa Giardina Papa, "Technologies of Care" (2016), downloadable at Rhizome, http://rhizome.org/editorial/2016/oct/04/the-download-technologies-of-care/.

18. Franco "Bifo" Berardi, Precarious Rhapsody, Semiocapitalism and the Pathologies of PostAlpha Generation. (London: Minor Composition, 2009), 32-33.

19. Ibid., 33. 


\section{AUTHOR BIOS}

\section{TUNG-HUI HU}

Tung-Hui $\mathrm{Hu}$ is the author of a study of digital culture, A Prehistory of the Cloud (MIT Press, 2015), and three books of poetry, most recently Greenhouses, Lighthouses (Copper Canyon Press, 2013). He is an associate professor of English and digital studies at the University of Michigan.

\section{ELISA GIARDINA PAPA}

Elisa Giardina Papa is an Italian artist whose work investigates gender, sexuality, and labor in relation to neoliberal capitalism and the threshold of the Global South. Her work has been exhibited and screened at MoMA (New York), Whitney Museum (Sunrise/Sunset Commission), Seoul Mediacity Biennale 2018, Unofficial Internet Pavilion of $54^{\text {th }}$ Venice Biennial, XVI Quadriennale di Roma, The Flaherty NYC, among others. She lives and works in New York and Sant'Ignazio (Sicily).

http://www.elisagiardinapapa.org/. 